\title{
Isolation of Natural Dyes from Hibiscus Rosa Sinensis and Marigold Flower and Dyeing Properties of the Dyes On Cotton Cloth
}

\author{
${ }^{1}$ R. Ramprasath, ${ }^{2}$ G. Geetha Kavi and ${ }^{3}$ T.Selva Rathi \\ Centre for Research and P.G. Studies in Chemistry, Ayya Nadar Janaki Ammal College, Sivakasi
}

\begin{abstract}
In this study deals with the isolation of natural dyes from hibiscus rosa sinensis and marigold flowers. There are different methods are used to synthesis the natural dyes on each flower. Then they are analysed by GC-MS, UV-Visible and IR Spectroscopy instrumental analysis. The instrument anlaysis reveals the structural conformation of natural dye collected from each dye. The mordant are important chemical component which is used to add with natural dye to enhance the colour strength of natural dye collected from the above flowers. In this project we use the alum, potassium dichromate, copper chloride and stannous chloride are used as mordant to increase the colour strength of each natural dye collected from the concerned flowesr. The colour strength is analysed with DATAColor Spectrophotomete. Wast fastness, Xenon fastness test are also carried out. From above test we conclude the strength of colour is increased by means of the stannous chloride mordent used compared to other mordants applied to the cotton dyed with the natural dyes extracted from the hibiscus rosa sinensis and marigold flower.
\end{abstract}

\section{Introduction}

A dye is a colored substance applied to the substrate like textile, leather, plastic and paper etc., with its affinity power. The dye is generally applied in an aqueous solution, and may require a mordant to improve the fastness of the dye on the fiber. Dye is defined as the compound containing chromophore and auxochrome groups. Chomophore group is responsible for dye colour due to their unsaturation. Auxochrome ${ }^{[1]}$ group is responsible for dye fibre reaction.

Natural dyes ${ }^{[2-5]}$ are dyes (or) colorants derived from plants, invertebrates (or) minerals, The majority of natural dyes are vegetable dyes from plant sources. Natural dyes are more eco-friendly than the synthetic dyes, that is, synthetic dyes can produce pollutants. Certain diazo dyes ${ }^{[5-8]}$ are carcinogenic and natural dyes are also free from carcinogenic components. Most natural dyes are known as antioxidants. Natural Dyes do not cause any sort of irritation.Natural dyes have pharmacological effects and possible health benefits.

The shades produced by natural dyes/colourants are usually soft, lustrous and soothing to the human eye. Depending on the mordants used with one dye can give variety of colors which also depends on the source of the dye. They are obtained from renewable sources also. Natural dyes cause no disposal problems, as they are biodegradable ${ }^{[9-12]}$. Some of the natural dyes are enhanced with age, while synthetic dyes fade with time. Natural dyes bleed but do not stain other fabrics, turmeric being an exception. Natural dyes are usually moth proof and can replace synthetic dyes ${ }^{[13-20]}$ in kids garments and food-stuffs for safety.

\section{Aim and objectives of present work}

1. To isolate dye extract from hibiscus rosa sinensis and marigold flower by organic solvent extract method.

2. To apply the isolated dye extract from hibiscus rosa sinensis and marigold flower on cotton dyeing.

3. To investigate the presence of dye extract from hibiscus rosa sinensis by using UV-Visible and IR Spectroscopy

4. To investigate the presence of dye extract from marigold flower by using Gas chromatography - Mass spectrometry chromatogram.

5. To study the spectroscopic measurements of dyed sample with CIE Colour parameter by using DATAColor Tool Software.

6. To analyse the fastness properties test of dye extract from marigold flower through Xenon Test (ISO Norm B02)

7. To analyse the fastness properties test of dye extract from marigold flower through Wash Fastness Test (ISO Norm B02) 


\section{Experimental Methods}

Flowers of hibiscus Rosa sinensis are collected from the places located in and around Rajapalayam and marigold flowers are collected from the places located in Sivakasi. The hibiscus rosa sinensis were kept in cold $\left(20^{\circ} \mathrm{C}\right)$ and darkstorage until processed and extracted into methanol (S D Fine, 96\% (v/v)), keeping them overnight. Anthocyanin extraction was extracted from hibiscus rosa sinensis by $\mathrm{HCl}$ or citric acid solvents. About $0.1 \% \mathrm{HCl}(\mathrm{v} / \mathrm{v})$ or $4.0 \%$ citric acid (w/v) and flower in methanol is taken for 2 to 3 hours at room temperature, in darkness without heating or stirring. The mixture was filtered on a Buchner funnel and the remaining solids were washed with $0.1 \% \mathrm{HCl}$ (or) $4.0 \%$ citric acid in methanol until a clear solution was obtained. The combined filtrates were dried using a rotary evaporator at $55^{\circ} \mathrm{C}$. The concentrate was dissolved in distilled water and the solution obtained was used for dyeing.

There are two types of conventional extraction of natural dye from marigold flowers. In the first method called aqueous extraction method, an aqueous solution of the dried flowers $(3.3 \mathrm{~g}$ in $100 \mathrm{~mL}$ distilled water) are prepared and the extraction process was carried out at a temperature range of $50^{\circ} \mathrm{C}-95^{\circ} \mathrm{C}$ for 2 hours. In the second method called Aqueous-Ethanol extraction method, the finely crushed dry flowers (powdered form) were taken in three different $250 \mathrm{ml}$ conical flasks containing 60\%, 70\% and 100\% Ethanol respectively. The flasks were incubated over a water bath for 4 hours at $68^{\circ} \mathrm{C}$. There is one soxhlet extraction method is are also available to avoid the filtration of the solvent and residue and also to obtain better efficiency of separation. The organic solvents such as Ethanol, Methanol and Hexane were used for this extraction method. The weighed quantity of feed (F) or raw material and measured volume of solvent (S) were taken in certain F/S ratio. The raw material (finely crushed dry flower) was kept in thimble of Soxhlet extractor and the solvent was poured in the round bottom flask and a condenser with high flow rate of water is fitted over it. The extraction was carried for 4-5 hours and the volume of the solutions thus obtained was measured. For the evaporation of solvent, a rotary evaporator was used and the remaining dye extract is weighed

\subsection{Scouring of cotton and silk}

Cotton and silk fabrics were washed with solution containing $0.5 \mathrm{~g} / \mathrm{L}$ sodium carbonate and $2 \mathrm{~g} / \mathrm{L}$ nonionic detergent (Labolene) for $30 \mathrm{~min}$, keeping the material to liquor ratio at $1: 50$. The scoured material was thoroughly washed with tap water and dried at room temperature in shade.

\subsection{Mordanting}

Weighed cotton/silk samples were treated with different metal salts, only premordanting with metal salts was carried out. The percentage of mordant used is $2 \%$ solution. The fabric was immersed in the mordant solution and then it was brought to heating and the temperature of the solution was raised to $60^{\circ} \mathrm{C}$ in a half an hour and maintained in this temperature for $30 \mathrm{~min}$. Mordanted cotton and silk should be used immediately because some mordants are very sensitive to light.

\subsection{Dyeing}

The conventional dyeing technique was used for the dyeing of mordanted as well as for the nonmordanted fabrics and yarn samples. The cotton samples were dyed directly with the dye extract by keeping the $\mathrm{M}$ : $\mathrm{L}$ ratio as 1:40; however in case of wool yarn, the $\mathrm{pH}$ ofthe dye extract was adjusted to 5 by adding Formic acid. The M: L ratio was kept as 1: 40 even in the case of wool dyeing. The dyeing process was carried out for 2 hours in a water bath at $85^{\circ}$.After the completion of dyeing; the samples were washed off with cold water and dried at the room temperature. The dyed samples were then dipped in a brine solution for dye fixing.

\subsection{Analysis of dyestuff, purity and yield}

Total anthocyanin extract derived from hibiscus rosa sinensis analysis was performed using a spectrophotometric differential $\mathrm{pH}$ method. The supernatant was collected and its absorbance was read at 510 $\mathrm{nm}$. The spectra for the anthocyanin extracted from Hibiscus rosa sinensis recorded in UV-visible spectropectrophotometer (Hekios a Thermo Electron Corp.). and Fourier transform infra-red spectroscopy with Vertex 70 model, Bruker, Germany. Spectrophotometric measurements of the dyed samples were done with a Datacolor CHECK Pro and evaluated by the Datacolor TOOLS software from Datacolor. The measured values were the average of 5 measurements. As standard illuminate $\mathrm{D}_{65} / 10$ (daylight) was used and a tolerance of CMC $2: 1$.

\subsubsection{Xenon Test}

To determine the light fastness of the dyed cotton fabric xenon test according to ISO-Norm B02 was done. The prepared samples had the size $1.5 \times 7 \mathrm{~cm}$. 


\subsubsection{Wash Fastness Test}

The wash fastness was ascertained by a wash fastness test according to ISO $105-\mathrm{C}$. The sample was together with an additional adjacent fabric, a multistripe with 6 different fabric samples (diacetate, cotton, polyamide, polyester. acryl and wool) washed for $30 \mathrm{~min}$ at $60^{\circ} \mathrm{C}$, with $50 \mathrm{ml}$ of detergent solution $(4 \mathrm{~g}$ detergent /1). 25 steel balls were added. A common household detergent was used as washing liquid. The washed samples were rinsed and dried.

Afterwards the dyed cotton samples were analysed on colour change and the multistripe adjacent fabrics were analysed on staining with the 5 grades grey-white scale in $\mathrm{D}_{65}$ illuminate. The $\mathrm{D}_{65}$ illuminent is taken and worked in Sivakasi Institute of Printing Technology (SIPT), Sivakasi.

\subsection{UV-Visible and ft- ir spectroscopic study}

\section{Result and Discussion}

UV-Visible spectra of anthocyanin extracted from hibiscus rosa sinensis at the same concentration but different $\mathrm{pH}$ is shown in the Table 3.1 and Figure 3.1. It shows the change a shift in $\mathrm{k}_{\max }$ by the addition of stannous salt. This is very apparent. The change in color profile after adding stannous salt to anthocyanin extracted from hibiscus rosa sinensis at different $\mathrm{pH}$ was due to change in $\mathrm{k}_{\max }$. Better chelation of Dye-Sn complex to the fabric is possibly responsible for good wash and light fastness.

TABLE 3.1: EFFECT OF PH ON DYE EXTRACT

\begin{tabular}{|c|c|c|c|c|c|c|c|}
\hline \multicolumn{7}{|c|}{ UNMORDANT } \\
\hline $\mathrm{pH}$ values & 3 & 4 & 5 & 6 & 7 & 8 & 9 \\
\hline$\lambda_{\max }$ & 520 & 525 & 545 & 546 & 560 & 578 & 565 \\
\hline $\mathrm{pH}$ values & 3 & 4 & 5 & 6 & 7 & 8 & 9 \\
\hline$\lambda_{\max }$ & 538 & - & - & 560 & - & - & 552 \\
\hline
\end{tabular}

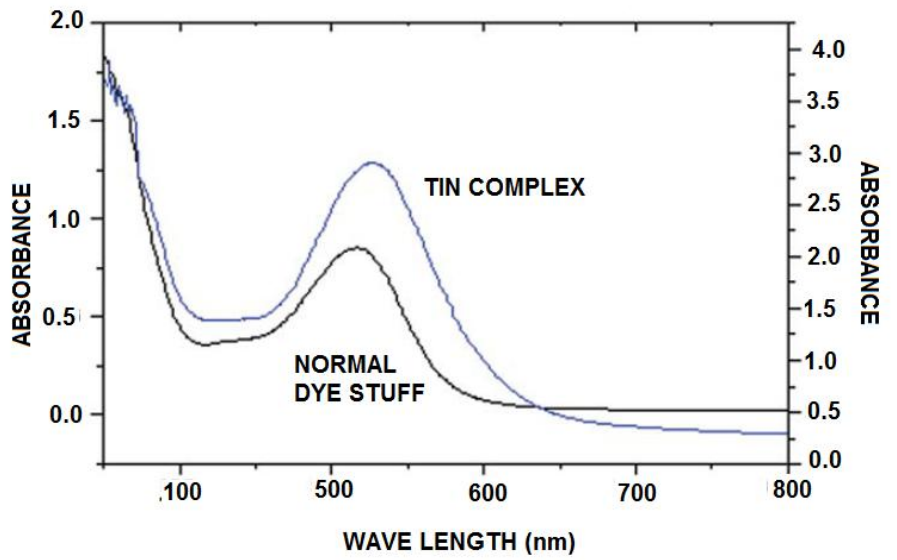

FIGURE 3.1: EFFECT OF pH ON ANTHOCYANIN EXTRACTED FROM HIBISCUS ROSA SINENSIS AND TIN COMPLEX

The FT-IR spectra of anthocyanin extracted from hibiscus rosa sinensis Tin-anthocyanin depict that anthocyanin dye shows intense peaks at $3500 \mathrm{CM}^{-1}$ indicates the hydroxyl group) and at $1710 \mathrm{~cm}^{-1}$ indicates the carbonyl group. While the Sn-chelated dye showed less intense peaks at the aforementioned values, through which it can be concluded that these changes are due to metal chelation by the $o$-hydroxy carbonyl moiety of the anthocyanin molecules. The changes in the IR Spectrum indicates the complex bond between tin and dyestuff. the changes are at $1628 \mathrm{~cm}^{-1}$ indicating aromatic $-\mathrm{C}=\mathrm{C}-, 1220 \mathrm{~cm}^{-1}$ indicating $-\mathrm{O}-\mathrm{C}=\mathrm{O}-, 1127 \mathrm{~cm}^{-1}$ indicating C-C- and $929 \mathrm{~cm}^{-1}$. It is shown in Figure 3.2 .

\subsection{Determination of chemical compound of marigold flower by gas chromatography-mass spectrometry analysis}

GC-MS of dye extracts obtained from the marigold flowers using solvents led to the identification of various compounds. The chromatogram of aqueous extract is shown in the Figure 3.2. The various compounds detected by GC-MS in aqueous extracts are shown along with their respective retention time and area percentage in Tables 3.2. The presence of various components with different retention (RT) times was confirmed by GC-MS spectra. 


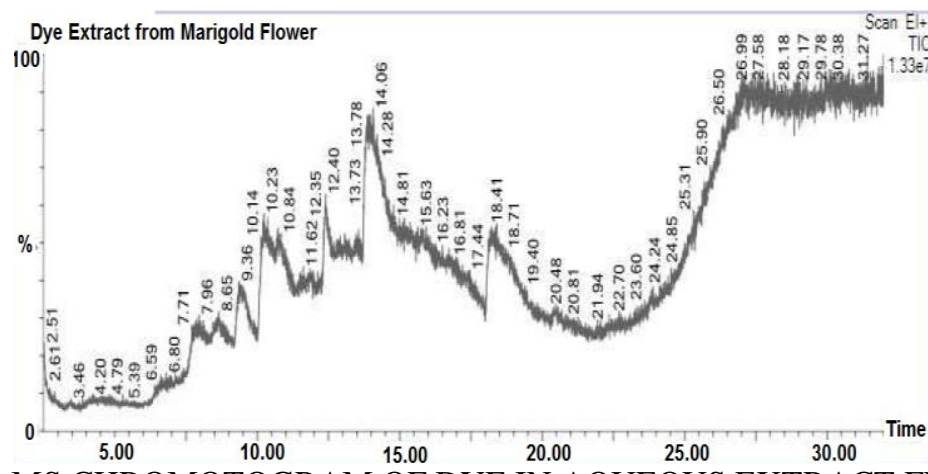

FIGURE 3.2: GC-MS CHROMOTOGRAM OF DYE IN AQUEOUS EXTRACT FROM MARIGOLD FLOWERS

The mass spectroscopy analyzes the components eluted at different times to identify the structure and the nature of the compounds. The fragmentation of large compound into small ones gives rise to appearance of peaks at different $\mathrm{m} / \mathrm{z}$ ratios. These mass spectra act as a fingerprint of the very compound that can be identified from the library. The results of the GC-MS analysis showed the presence of various alkaloids, glycosides, flavonoid derivatives, phenols, reducing sugars, steroids and terpenoids and can be further analyzed for more specifications.

TABLE 3.2: COMPOUNDS IDENTIFIED BY GC- MS CHROMATOGRAM IN THE AQEOUS DYE EXTRACT FROM MARIGOLD FLOWER

\begin{tabular}{|c|c|c|c|c|c|}
\hline S.No. & COMPOUND & MOL. WT & $\begin{array}{l}\text { MOL. } \\
\text { FORMULA }\end{array}$ & $\begin{array}{c}\text { RT } \\
(\mathbf{M I N})\end{array}$ & $\begin{array}{c}\text { AREA } \\
(\%)\end{array}$ \\
\hline 1. & $\begin{array}{l}\text { 10,12-Dimethyl-1,4,7-trioxa-10,12- } \\
\text { diazacyclotetradecan-11-one }\end{array}$ & 246 & $\mathrm{C}_{11} \mathrm{H}_{22} \mathrm{O}_{4} \mathrm{~N}_{2}$ & 10.232 & 9.197 \\
\hline 2. & $\begin{array}{l}\text { 2-oxo-2-(4-phenylphenyl)ethyl 2- } \\
\text { hydroxy-3-methylbenzoate }\end{array}$ & 346 & $\mathrm{C}_{22} \mathrm{H}_{18} \mathrm{O}_{4}$ & 10.732 & 8.2189 \\
\hline 3. & $\begin{array}{l}\text { 6-Tert-butyl-8-methyl-1H,2H,3H- } \\
\text { cyclopenta[c]chromen-4-one }\end{array}$ & 256 & $\mathrm{C}_{17} \mathrm{H} 20 \mathrm{O}_{2}$ & 11.617 & 3.468 \\
\hline 4. & $\begin{array}{l}\text { 2,2-Dimethyl-5-[2-(2-tri } \\
\text { methylsilylethoxymethoxy)-propyl]- } \\
{[1,3] \text { dioxol }}\end{array}$ & 318 & $\mathrm{C}_{15} \mathrm{H}_{30} \mathrm{O}_{5} \mathrm{Si}$ & 12.397 & 6.262 \\
\hline 5. & 2-n-Hexylthio-5-methyl-imidazoline & 200 & $\mathrm{C}_{10} \mathrm{H}_{20} \mathrm{~N}_{2} \mathrm{~S}$ & 12.923 & 3.575 \\
\hline 6. & I-Propyl tricosanoate & 396 & $\mathrm{C}_{26} \mathrm{H}_{52} \mathrm{O}_{2}$ & 13.563 & 4.175 \\
\hline 7. & $\begin{array}{l}\text { Alpha.-d-glucopyranoside, O-.alpha.-D- } \\
\text { glucopyranosyl }\end{array}$ & 504 & $\mathrm{C}_{18} \mathrm{H}_{32} \mathrm{O}_{16}$ & 14.603 & 30.370 \\
\hline 8. & Beta-D-lyxofuranoside, thio-decyl & 306 & $\mathrm{C}_{15} \mathrm{H}_{30} \mathrm{O}_{4} \mathrm{~S}$ & 15.158 & 4.557 \\
\hline 9. & Benzoic acid, 4-hydroxy-3,5-dimethoxy & 198 & $\mathrm{C}_{9} \mathrm{H}_{10} \mathrm{O}_{5}$ & 18.230 & 3.167 \\
\hline 10. & Benzenemethanol, 3,4,5-trimethoxy & 198 & $\mathrm{C}_{10} \mathrm{H}_{14} \mathrm{O}_{4}$ & 18.410 & 3.697 \\
\hline
\end{tabular}

\subsection{SPECTROPHOTOMETRIC MEASUREMENTS}

Spectrophotometric measurements of the dyed samples were done with a Datacolor CHECK Pro and evaluated by the Datacolor TOOLS software from Datacolor. The following informations were gathered from the CIE Colour system : The K/S values were for both unmordanted and mordanted samples the same. The post mordanted samples were little bit lighter in colour due to the slightly higher $\mathrm{L}^{*}$ value. However the $\mathrm{L}^{*}$ values for both unmordanted and mordanted samples were high compared to the low values of $\mathrm{C}^{*}$. Considering both values $\mathrm{L}^{*}$ and $\mathrm{C}^{*}$ together the shades of dye extract derived from from marigold flowers dyed cotton weave fabric were light and weak in colour saturation. The $\mathrm{a}^{*}$ and $\mathrm{b}^{*}$ values indicate the shades of reddish yellow.

The mordanted samples were compared to the unmordanted samples slightly more colour saturated $\left(\mathrm{C}^{*}\right)$ and the mordant bind more dyestuff on the cotton fabric means more colour absorbed on the cotton fabric $(\Delta \mathrm{E})$. The shade is more yellowish and less reddish. The different mordants not only caused the differences in hue color and significant changes in K/S values but also $\mathrm{L}^{*}$ values and brightness index values. Most of the metal salts exhibited the higher K/S values due to their ability to form coordination complexes with the dye molecules. The strong coordination tendency between the fibres and the dye results in high uptake of dye. The results for the colorimetric measurements of cotton weave fabric, dyed with extract derived from marigold flowers and dye from hibiscus rosa sinensis are given in Table 3.3. 
TABLE 3.2: COLOUR COORDINATION OF THE DYED COTTON FABRICS

\begin{tabular}{|c|c|c|c|c|c|}
\hline \multicolumn{6}{|c|}{ FROM MARIGOLD FLOWER } \\
\hline & \multirow{2}{*}{$\begin{array}{c}\text { UN- } \\
\text { MOR- } \\
\text { DANT }\end{array}$} & \multicolumn{4}{|c|}{ MORDANT } \\
\hline & & ALUM & $\mathrm{CuSO}_{4}$ & $\mathrm{~K}_{2} \mathrm{Cr}_{2} \mathrm{O}_{7}$ & $\mathrm{SnCl}_{2}$ \\
\hline $\mathrm{K} / \mathrm{S}$ & 18.17 & 10.01 & 11.23 & 15.20 & 14.08 \\
\hline $\mathrm{L}^{*}$ & 31.22 & 12.37 & 70.10 & 68.25 & 78.12 \\
\hline $\mathrm{A}^{*}$ & 60.18 & 7.23 & 1.88 & 1.25 & -1.56 \\
\hline$b^{*}$ & 4.44 & 6.55 & 29.05 & 28.55 & 21.75 \\
\hline $\mathrm{C}^{*}$ & 45.23 & 11.20 & 55.00 & 51.30 & 11.30 \\
\hline $\mathrm{h}^{*}$ & 5.36 & 2.58 & 1.45 & 8.46 & 8.15 \\
\hline$\Delta \mathrm{E}^{*}$ & 16.25 & 63.15 & 11.55 & 1.56 & 0.79 \\
\hline \multicolumn{6}{|c|}{ FROM HIBISCUS ROSA SINENSIS } \\
\hline $\mathrm{K} / \mathrm{S}$ & 66.71 & 60.23 & 54.26 & 61.85 & 149.2 \\
\hline $\mathrm{L}^{*}$ & 41.52 & 41.52 & 41.76 & 41.25 & 37.11 \\
\hline $\mathrm{A}^{*}$ & 40.86 & 40.58 & 38.47 & 19.88 & 19.25 \\
\hline $\mathrm{b}^{*}$ & 2.45 & 2.75 & 2.75 & 12.77 & -16.88 \\
\hline $\mathrm{C}^{*}$ & 41.23 & 40.27 & 38.96 & 21.98 & 25.34 \\
\hline $\mathrm{h}^{*}$ & 3.14 & 3.14 & 3.17 & 32.66 & 320.16 \\
\hline
\end{tabular}

It shows the CIEL $a^{*} b *$ values of dyed cotton fabrics with aqueous dye extract derived from marigold after premordanting with different mordants, the dyeing after pretreatment with different inorganic salts caused shade change from dark pink, brown to purple. Varied hues of color were obtained from premordanting the cotton with alum, $\mathrm{SnCl}_{2}, \mathrm{CuSO}_{4}$, and $\mathrm{K}_{2} \mathrm{Cr}_{2} \mathrm{O}_{7}$ and were dyed by aqueous dye extract from marigold flower as shown in the Table 3.1. The different mordants not only cause difference in hue color and significant changes in $\mathrm{K} / \mathrm{S}$ values but also $\mathrm{L}$ values and brightness index values. The best values for K/S measured for cotton were obtained with stannous chloride.

\subsection{FASTNESS PROPERTIES TESTS}

Natural dyes have poor to moderate wash fastness as compared to synthetic dyes having moderate to excellent color fastness properties. Light fastness of many natural dyes, particularly which are extracted from flower parts are found to be poor to medium. Two fastness property tests were done on the dyed cotton samples. Xenon test (ISO-Norm B02) and wash fastness test (ISO 105-C).

\subsubsection{XENON TEST (ISO-NORM B02)}

The xenon test samples are graded between the ranges from 1-8, where 1 is very bad and 8 is very good. The results are listed in the Table 3.3. The $\mathrm{D}_{65}$ illuminent is taken and worked in Sivakasi Institute of Printing Technology (SIPT), Sivakasi. The light fastness properties of aqueous dye extract from marigold flower dyed on cotton for mordanted samples except Sn-complex have lower effect.

TABLE 3.3: THE XENON LIGHT FASTNESS TEST

\begin{tabular}{|c|c|c|c|c|}
\hline \multirow{2}{*}{ UN- MOR -DANT } & \multicolumn{5}{|c|}{ MORDANT } \\
\cline { 2 - 5 } & ALUM & CuSO $_{\mathbf{4}}$ & $\mathbf{K}_{\mathbf{2}} \mathbf{C r}_{\mathbf{2}} \mathbf{O}_{\mathbf{7}}$ & $\mathbf{S n C l}_{\mathbf{2}}$ \\
\hline \multicolumn{7}{|c|}{ FROM MARIGOLD FLOWER } \\
\hline 2 & 3 & 3 & 3 & 5 \\
\hline 2 & 3 & 3 & 4 & 6 \\
\hline
\end{tabular}

The light fastness was improved by post mordanting the samples. The mordanted samples of dye extract from marigold flower were compared with their unmordanted counterparts each with 1 grade better. The lower results of the light fastness for dye extract from marigold flower could be interpreted due to the high sensitivity of aqueous dye extract from marigold light exposure and its higher and purer amount in the Tin complexed dye.

The reason may be the small molecule size and the resulting lower affinity towards the cotton fibres.

\subsubsection{WASH FASTNESS TEST (ISO 105 - C)}

The results for the wash fastness test according to ISO 105-C are given in Table 3.4. The grade range is from 15 , where 1 is very bad and 5 very good. The $\mathrm{D}_{65}$ illuminent is taken and worked in SIPT, Sivakasi. 
TABLE 3.4: THE WASH FASTNESS TEST

\begin{tabular}{|c|c|c|c|c|}
\hline \multirow{2}{*}{ UN- MOR -DANT } & \multicolumn{4}{|c|}{ MORDANT } \\
\cline { 2 - 5 } & ALUM & $\mathbf{C u S O}_{\mathbf{4}}$ & $\mathbf{K}_{\mathbf{2}} \mathbf{C r}_{\mathbf{2}} \mathbf{O}_{\mathbf{7}}$ & $\mathbf{S n C l}_{\mathbf{2}}$ \\
\hline \multicolumn{6}{|c|}{ FROM MARIGOLD FLOWER } \\
\hline \multicolumn{7}{|c|}{ FROM HIBISCUS ROSA SINENSIS } \\
\hline 1 & $3-4$ & 4 & $3-4$ & $4-5$ \\
\hline
\end{tabular}

The results for the colour change of unmordanted and mordanted samples dye extract from marigold flower dyed cotton fabrics were only a grade 1 . Almost no colour was left on the cotton samples after washing at $60^{\circ} \mathrm{C}$ for $30 \mathrm{~min}$. Whereas the colour change gave some low quality effect for both dye extract from marigold flower dyed on cotton fabric the staining. The lower effect of colour change in washing test for dye extract from marigold flower dyed on cotton weave fabric is interpreted by the lack of functional groups and the relative small molecule sizes of the dye extract from marigold flower and their consequential low affinity towards the textile fibres.

\section{Conclusion}

This present study indicates the suitable storage condition for dye extract from marigold flower and hibiscus rosa sinensis form is under acidic conditions and should be kept in the dark. Other factors found to affect the pigment stability were light and elevated temperature which caused increased pigment degradation. From the GC-MS Spectroscopy, the various alkaloids, glycosides, flavonoid derivatives, phenols, reducing sugars, steroids and terpenoids presented in the dye extract from marigold flower is investigated and identified From the UV-Visible and FT-IR Spectroscopy, it is nown that the better chelation of anthocyanin dye in extracted from Hibiscus rosa sinensis Dye-Sn complex to the fabric is possibly responsible for good wash and light fastness.

From the spectroscopic measurements of dyed sample it is known that the colour uptake $(\Delta \mathrm{E})$ for the mordanted samples were again slightly higher than for the unmordanted samples as K/S value was higher for mordanted samples. The unmordanted samples were compared with the post mordanted samples with alum slightly lighter due to their higher $\mathrm{L}^{*}$ value. The $\mathrm{C}^{*}$ values for colour saturation were for the post mordanted samples little lower, which means the colour saturation decreases with mordanting. The slight negative values of $\mathrm{a}^{*}$ and the more positive $\mathrm{b}^{*}$ values indicate shades of greenish yellow and slightly more greenish and less yellowish for the mordanted samples. The best values for K/S measured for cotton were obtained with stannous chloride.

Analysing the fastness properties test of dye extract from marigold flower through Xenon Test (ISO Norm B02) shows the lower results of the light fastness for aqueous dye extract from marigold flower and hibiscus rosa sinensis which could be interpreted due to the high sensitivity of Tin-dye extract in light exposure and its higher and purer amount in this dye. Analysing the fastness properties test of Tin- dye extract from marigold flower through Wash Fastness Test (ISO Norm B02) shows the better effect of colour change in washing test than other mordants. Dye extract from marigold flower can be used as dyestuff. 